\title{
New calls for proposals in the field of health launched by the Executive Agency for Health and Consumers
}

Eurosurveillance editorial team (eurosurveillance@ecdc.europa.eu) ${ }^{1}$

1. European Centre for Disease Prevention and Control (ECDC), Stockholm, Sweden

Citation style for this article:

Eurosurveillance editorial team. New calls for proposals in the field of health launched by the Executive Agency for Health and Consumers. Euro Surveill.

2011;16(10): pii=19811. Available online: http://www.eurosurveillance.org/ViewArticle. aspx?Articleld=19811

Article published on 10 March 2011

On 3 March 2011 the Executive Agency for Health and Consumers (EAHC) launched the calls for proposals for joint actions, operating grants, projects and conferences based on the 2011 Work Plan of the Health Programme adopted on 22 February 2011.

These calls for proposals are open to all legally established organisations such as non-governmental organisations, public sector bodies, public administrations, universities, higher education establishments, etc. established in one of the 27 EU countries or in EFTA countries members of the European Economic Area (Iceland, Liechtenstein, and Norway) or in Croatia.

The deadline for submitting applications is 27 May 2011.

For receiving a European grant, projects generally have to contribute at least to one of the three main objectives of the Health Programme (2008-2013): to improve citizens' health security, to promote health, including the reduction of health inequalities, to generate and disseminate health information and knowledge.

The 2011 work plan gives more emphasis and resources to a focused cooperation with the European Union (EU) Member States. The amount of EUR 17,040,000 will be dedicated to the funding of five joint actions: (i) health technology assessment, (ii) e-health, (iii) organ transplantation, (iv) patient safety, and (v) rare diseases.

Normally, for projects and grants, up to $60 \%$ of the eligible costs can be covered by the EU contribution and at least $40 \%$ of project costs must be funded from partners' sources. In cases of exceptional utility, the EU contribution can go up to $80 \%$ of the eligible costs. In case of joint actions, the EU contribution cannot exceed $50 \%$, excepting cases of exceptional utility where it can go up to $70 \%$. Exceptional utility may occur when activities have a very significant European added value in the areas indicated in the work plan. Conferences will be eligible for co-financing by the EU of up to EUR 100,000 with a maximum $50 \%$ of the total budget of the conference.
More information is available on the website of the Executive Agency for Health and Consumers at the following address: http://ec.europa.eu/eahc/health/ index.html 